\title{
Incidence and risk factors for exacerbations of asthma during pregnancy
}

\author{
This article was published in the following Dove Press journal: \\ Journal of Asthma and Allergy \\ 3 May 2013 \\ Number of times this article has been viewed
}

\section{Zarqa Ali \\ Charlotte Suppli Ulrik \\ Department of Pulmonary Medicine, Hvidovre Hospital and University of Copenhagen, Copenhagen, Denmark}

Background: Asthma is one of the most common chronic diseases among pregnant women. Acute exacerbations of asthma during pregnancy have an unfavorable impact on pregnancy outcome. This review provides an overview of current knowledge of incidence, mechanisms, and risk factors for acute exacerbations of asthma during pregnancy.

Methods: A narrative literature review was carried out using the PubMed database.

Results: During pregnancy, up to $6 \%$ of women with asthma are hospitalized for an acute exacerbation. The maternal immune system is characterized by a very high T-helper-2:T-helper-1 cytokine ratio during pregnancy and thereby provides an environment essential for fetal survival but one that may aggravate asthma. Cells of the innate immune system such as monocytes and neutrophils are also increased during pregnancy, and this too can exacerbate maternal asthma. Severe or difficult-to-control asthma appears to be the major risk factor for exacerbations during pregnancy, but studies also suggest that nonadherence with controller medication and viral infections are important triggers of exacerbations during pregnancy. So far, inconsistent findings have been reported regarding the effect of fetal sex on exacerbations during pregnancy. Other risk factors for exacerbation during pregnancy include obesity, ethnicity, and reflux, whereas atopy does not appear to be a risk factor.

Discussion: The incidence of asthma exacerbations during pregnancy is disturbingly high. Severe asthma - better described as difficult-to-control asthma - nonadherence with controller therapy, viral infections, obesity, and ethnicity are likely to be important risk factors for exacerbations of asthma during pregnancy, whereas inconsistent findings have been reported with regard to the importance of sex of the fetus.

Keywords: acute exacerbations, pregnancy, asthma severity, incidence, risk factors

\section{Introduction}

Asthma is a major health problem worldwide. ${ }^{1}$ Its prevalence is particularly high among women, ${ }^{2}$ and it is probably the most common chronic disease seen in pregnant women. Asthma represents a potentially serious medical condition during pregnancy, not least because exacerbations of asthma during pregnancy have been associated with unfavorable pregnancy outcomes. ${ }^{3}$

More than half of women with asthma experience an increase in symptoms and medication requirements in the premenstrual phase (luteal phase). ${ }^{4}$ The incidence of asthma is higher around menopause, and possibly also in women reporting use of postmenopausal hormone replacement therapy. ${ }^{5}$ This indicates that changes in the levels of sex-specific hormones in women have a significant impact on asthma. In keeping with this, the substantial fluctuations in, not only sex-specific, hormones seen during pregnancy must be expected to have an impact on asthma as well.
Correspondence: Charlotte Suppli Ulrik Virum Overdrevsvej 13, DK-2830 Virum, Denmark Email csulrik@dadlnet.dk 
The aim of this review is to provide an overview of the current knowledge of incidence of asthma exacerbations, underlying mechanisms, and risk factors for acute exacerbations of asthma during pregnancy.

\section{Methods}

For this narrative literature review, a series of searches was carried out and last updated January 2013, using the PubMed database. The strategy was intended to be broad in order to maximize the capture of citations for peer-reviewed publications relevant to asthma and pregnancy. The PubMed searches were carried out using the following algorithm of medical subject headings: asthma and asthma-like symptoms, or asthma exacerbations and pregnancy, and the searches were repeated with these terms in combination with incidence, pathogenesis, mechanisms, risk factors, pregnancy complications, immune function, sex hormones, premenstrual, fetal sex, and fetal outcome. Articles published in English were included in the review, provided they reported data from cohort studies, prospective or retrospective, of pregnant women with physician-diagnosed asthma (confirmed or self-reported).

\section{Results}

\section{Physiological changes during pregnancy}

Multiple physiologic changes during pregnancy interact with the pathophysiology of asthma. As the uterus increases in size, it pushes the diaphragm upward, which results in a reduction in the functional residual capacity (on average $0.45 \mathrm{~L}$ ) due to a progressive decrease in expiratory reserve volume. ${ }^{6}$ However, the total lung capacity decreases minimally because the function of the diaphragm and thoracic muscles is impaired, and the widening of the thoracic cage results in an increased inspiratory capacity. Pregnancy also results in a $15 \%$ increase in maternal metabolic rate, which is met by a $20 \%$ increase in oxygen consumption. To compensate for the increased oxygen demand of pregnancy, the minute volume is increased by $40 \%-50 \%{ }^{7}$ This relative hyperventilation is due to an increase in tidal volume driven by the stimulatory effect of progesterone on the respiratory center. ${ }^{8}$ This occurs already in the first trimester of pregnancy, and remains constant or increases slightly as pregnancy progresses. ${ }^{9}$ Hyperventilation leads to respiratory alkalosis that is compensated by metabolic acidosis. Typical blood gases measured in early pregnancy are partial pressure of $\mathrm{CO}_{2}$ of $28-32 \mathrm{mmHg}$ and partial pressure of $\mathrm{O}_{2}$ of 106-110 mmHg, with a $\mathrm{pH}$ of 7.40-7.45. Pregnancy does not lead to a decline in forced expiratory volume in 1 second $\left(\mathrm{FEV}_{1}\right)$ or peak expiratory flow rate (PEFR). ${ }^{10}$
Similar to nonpregnant women with asthma, the $\mathrm{FEV}_{1}$ and PEFR may therefore be used for monitoring asthma control during pregnancy. ${ }^{11}$

\section{Maternal immune function during pregnancy}

Asthma is characterized by an altered immune response, and T-helper-2 (Th2) effector lymphocytes produce cytokines that regulate immunoglobulin (Ig)E synthesis, activate eosinophils and mast cells, and upregulate adhesion molecule expression. Eosinophils contribute to many of the pathological processes that stimulate vasomotor activity, bronchoconstriction, and the secretion of mucus during asthma. ${ }^{12-14}$ In 1993, Wegmann et a ${ }^{15}$ proposed that a shift towards Th2-mediated immunity, particularly at uterine sites during pregnancy, inhibits T-helper 1 immune responses and prevents rejection of the fetus by the maternal immune system. Presently, it is generally accepted that human pregnancy is associated with a shift away from cell-mediated immunity and T-helper 1-type cytokine production and towards humoral immunity Th2-type immune responses, ${ }^{16}$ which is essential for fetal survival, ${ }^{17}$ but incompletely understood. ${ }^{16}$ The Th2 upregulation may exacerbate maternal asthma. Other alterations in the maternal immune system during pregnancy, such as the proportion of cells of the innate immune system, including monocytes and neutrophils, may contribute to changes in asthma expression. ${ }^{18,19}$ Pregnancy is also associated with an increase in the number of cells of the innate immune system in maternal blood. ${ }^{20,21}$ It is possible that changes in circulating immune cell profiles during pregnancy could exacerbate maternal asthma.

\section{Incidence of acute exacerbation of asthma during pregnancy}

For decades, studies have described the incidence of asthma exacerbations during pregnancy. ${ }^{22}$ The median percentage of women hospitalized for asthma during pregnancy was $5.8 \%$ (2.4\%-8.2\% interquartile range) in a meta-analysis published in 2006 and based on eight prospective cohort studies. ${ }^{22}$ Schatz et a ${ }^{23}$ studied 330 asthma patients (366 pregnancies), prospectively managed women, to determine the effect of pregnancy on asthma. Asthma was assessed by (1) daily symptom and medication diaries, and (2) monthly spirometry during pregnancy and for 3 months postpartum. This study showed that asthma worsened during pregnancy in $35 \%$ of the women, improved in $28 \%$, and was unchanged in $33 \%$, forming the basis of the general dogma that one-third 
of women experience a worsening of their asthma during pregnancy, one-third have no change, and one-third have an improvement in asthma during pregnancy. ${ }^{23}$

\section{Risk factors for asthma exacerbation during pregnancy}

\section{Asthma severity}

Several studies have shown that the exacerbation rate increases with increasing asthma severity, and severe asthma appears to be the major risk factor for exacerbations during pregnancy. ${ }^{24,25}$ Schatz et al ${ }^{25}$ showed that acute exacerbations during pregnancy occurred in $12.6 \%$ of patients initially classified as having mild asthma, $25.7 \%$ of patients classified as having moderate asthma, and $51.9 \%$ of patients classified as suffering from severe asthma $(P<0.001)$. Subjects were considered to have mild asthma on enrollment if they fulfilled all of the following: (1) symptoms (cough, dyspnea, or wheezing) in the prior 6 months; (2) symptoms on fewer than 8 days during the 4 weeks before enrollment, not attributable to upper respiratory tract infections; (3) an enrollment $\mathrm{FEV}_{1} \geq 80 \%$ predicted; and (4) were not taking daily asthma medications. Subjects were considered to have moderate asthma on enrollment if they had any of the following: (1) symptoms on 8 or more days during the 4 weeks before enrollment, not attributable to upper respiratory tract infections; (2) an enrollment $\mathrm{FEV}_{1}$ of $60 \%$ to $80 \%$ predicted; or (3) requirement for at least one daily asthma medication other than oral corticosteroids for at least the 4 weeks before enrollment (ie, at least two puffs per day of inhaled $\beta$-agonist, at least one dose per day of theophylline, at least four puffs per day of inhaled ipratropium, or at least two puffs per day of inhaled cromolyn, nedocromil, or inhaled steroids). Subjects were considered to have severe asthma if either (1) their enrollment $\mathrm{FEV}_{1}$ was less than $60 \%$ predicted or (2) they required regular (daily or every other day) oral corticosteroids for at least 4 weeks before entry. An asthma exacerbation was defined as symptoms severe enough to result in a medical intervention, including hospitalization, unscheduled visits to a physician or emergency department (ED), or the prescription of oral corticosteroids (in patients who were not already on regular oral corticosteroids). In line with this, a study by Murphy et $\mathrm{al}^{24}$ showed that severe exacerbations requiring medical intervention occurred among $8 \%$ of women with mild asthma, $47 \%$ of women with moderate asthma, and $65 \%$ of women with severe asthma. In this study, a severe exacerbation was defined as a hospital admission, ED presentation, or an unscheduled visit to a doctor for asthma or a course of oral corticosteroids. Asthma severity was classified as mild, moderate, or severe based on the following criteria: Women with mild asthma had an $\mathrm{FEV}_{1}$ greater than $80 \%$ predicted, less than $25 \%$ variability in PEFR, no night-time or morning symptoms, infrequent $\beta_{2}$-agonist use, daytime symptoms less than four times per week, and no severe attacks in the previous year; women with moderate asthma had an $\mathrm{FEV}_{1}$ of $60 \%-80 \%$ predicted, less than $25 \%$ PEFR variability, night-time symptoms up to once per week, $\beta_{2}$-agonist use, and daytime symptoms on most days; and women with severe asthma had an FEV 1 less than $60 \%$ predicted, greater than $25 \%$ variability in PEFR, frequent night-time symptoms, morning and daytime symptoms every day, $\beta_{2}$-agonist use three to four times per day, and limited physical activity. The available studies, therefore, clearly suggest that more severe asthma, or at least difficultto-control asthma, is associated with an increased risk of asthma exacerbation during pregnancy.

\section{Exacerbations and nonadherence with asthma controller medication}

A descriptive web-based survey revealed that at least one-third of patients intended to be or were nonadherent with inhaled corticosteroid therapy during pregnancy, and $44 \%$ of women expressed concern about how both asthma medications and asthma attacks would affect their baby. ${ }^{26}$ The concerns about the possible negative impact of asthma medication on the baby may be an important factor when women decide for themselves whether or not to continue the medication during pregnancy. Nonadherence with controller medication for asthma is most likely a significant, but potentially preventable, problem among pregnant women. Psychosocial variables such as acceptance of illness and anxiety are known to influence asthma control and future risk, and adherence to therapy in nonpregnant patients with asthma. ${ }^{27,28}$ Fear of potential of teratogenic risks may also influence decisions about drug therapy in pregnancy and can modify adherence to medication; ${ }^{29}$ however, salbutamol and inhaled corticosteroids (ICS) are both recognized not to increase the teratogenic risk. ${ }^{30,31}$

In a study from Finland by Stenius-Aarniala et al, ${ }^{32}$ the risk of having an exacerbation was reduced by more than $75 \%$ among women who were regular users of ICS. Nonadherence with controller medication is, like in nonpregnant patients with asthma, a major challenge for health care providers taking care of pregnant women with asthma; and, furthermore, nonadherence with controller medication during pregnancy is associated with an increased risk of acute exacerbations during pregnancy. 


\section{Exacerbations triggered by viral respiratory infections}

Viral respiratory infections are risk factors for exacerbations of asthma, ${ }^{33,34}$ and viral infections are, therefore, likely to be an important trigger for asthma exacerbations during pregnancy. A prospective cohort study of 101 pregnant women with asthma and 77 women without asthma found that women with asthma were more likely to have an upper respiratory tract or urinary tract infection during pregnancy (35\%) than pregnant women without asthma (5\%), and that severe asthma was associated with significantly more infections than mild asthma. ${ }^{35}$ It has been hypothesized that changes in the maternal immune system during pregnancy may make pregnant women more susceptible to viral infections..$^{36}$ In the early stages of the H1N1 pandemic in the United States, $7 \%$ of hospitalized patients were pregnant, and $33 \%$ of these hospitalized women had asthma. ${ }^{37}$ A study by Rastogi et a ${ }^{38}$ suggested that prevention of infection might improve asthma symptoms among pregnant women by demonstrating an improvement in asthma symptoms during pregnancy among $50 \%$ of women who received an influenza vaccine, compared with improvement among only $15 \%$ of women not receiving the vaccine. Prevention of viral infections, including influenza vaccine, is likely to reduce the risk of having an asthma exacerbation during pregnancy. The American College of Obstetricians and Gynecologists and the Advisory Committee on Immunization Practices recommend influenza vaccination for women who are likely to become pregnant during the influenza season, regardless of trimester. In the 2004 revision of the guidelines, they expanded the recommendation from the second and third trimester to all three trimesters..$^{39,40}$ One randomized controlled trial conducted in Bangladesh that provided vaccination to pregnant women during the third trimester demonstrated a $29 \%$ reduction in respiratory illness with fever among the mothers and a $36 \%$ reduction in respiratory illness with fever among their infants during the first 6 months of life. In addition, infants born to vaccinated women had a $63 \%$ reduction in laboratory-confirmed influenza illness during the first 6 months of life. ${ }^{41}$ Available data do not indicate that influenza vaccine causes fetal harm when administered to a pregnant woman. One study of approximately 2000 pregnant women who received trivalent inactivated influenza vaccine during pregnancy demonstrated no adverse fetal effects and no adverse effects during infancy or early childhood. ${ }^{42}$

\section{Effect of fetal sex on maternal} risk of asthma exacerbation

Fetal sex is important scientifically to understand the mechanisms influencing maternal asthma and to guide future epidemiologic studies in the field of asthma and pregnancy as to whether they should adjust for fetal gender or not. Based on a blinded prospective study of 34 subjects with asthma completing a questionnaire, Beecroft et $\mathrm{a}^{43}$ have suggested that women pregnant with girls are more likely than those pregnant with boys to have increased symptoms of asthma during pregnancy. These self-reported data revealed that asthmatic women pregnant with a female fetus reported significantly more shortness of breath (72\% versus $31 \%)$, nocturnal awakening ( $55 \%$ versus $37 \%$ ), and general asthma symptoms (50\% versus $31 \%$ ) than women pregnant with a male fetus. Kwon et a ${ }^{44}$ have shown in a prospective study of 702 pregnant women with a diagnosis of asthma that worse maternal asthma is associated with carrying a female fetus, as assessed by greater airway lability, compared to women carrying a male fetus.

Murphy et $\mathrm{a}^{45}$ provided evidence from their study that in pregnancies complicated by asthma there is a fetal sexspecific effect on the maternal immune system, with adverse effects on placental function and female fetal growth, and furthermore, that the presence of a female fetus was associated with significantly increased maternal circulating monocytes. However, on the contrary, in a large cohort study comprising 11,257 pregnant women with asthma, Firoozi et a $1^{46}$ observed no significant increase in the rate of maternal asthma exacerbations or use of ICS and short-acting beta agonist during pregnancy among mothers of male and female fetuses. During the first trimester, $6.9 \%$ and $6.8 \%$ of women carrying a female and male fetus, respectively, had at least one asthma exacerbation, whereas it was $6.9 \%$ and $7.1 \%$, respectively, in the second trimester, and $4.0 \%$ and $3.7 \%$, respectively, in third trimester. The final logistic regression models showed no statistically significant differences in the rate of exacerbation, both during the entire pregnancy and for each trimester separately between mothers of female and male fetuses. The mean doses of short-acting beta agonist used per week in each trimester and during the entire pregnancy were similar in both groups. Similar proportions of women used ICS in each trimester and during the entire pregnancy in both groups (41.6\% in female and $41.0 \%$ in male fetuses during the entire pregnancy). Based on the results, the authors concluded that fetal gender is unlikely to affect maternal asthma during pregnancy to the point where acute care and medications are required more often among women pregnant with a female fetus. These results are in concordance with Baibergenova et al ${ }^{47}$ who found that fetal gender does not affect the risk of having an ED visit for asthma during pregnancy. This study was based on a large cohort of 109,173 live, singleton 
deliveries reconstructed from a hospital and an ambulatory care administrative database provided by the Canadian Institute for Health Information. A total of 530 women visited an ED due to asthma exacerbation: 258 were pregnant with a girl and 272 were pregnant with a boy. They made in total 704 ED visits (332 and 372, respectively). There were no major differences in sociodemographic characteristics among asthmatic women who visited an ED by gender of the fetus. Based on the conflicting observations reported, it appears that further studies are needed before valid conclusions can be drawn with regard to the possible association between fetal gender and risk of asthma exacerbation during pregnancy.

\section{Atopy, obesity, and other risk factors of exacerbation of asthma}

Atopy does not appear to be a risk factor for exacerbations during pregnancy. Stenius-Aarniala et $\mathrm{al}^{48}$ followed 198 pregnancies lasting 24 weeks or more in 181 women with asthma. Patients were divided into four severity groups on the basis of the treatment necessary to control asthma during pregnancy and the occurrence of acute exacerbations. An exacerbation was defined as an acute worsening of the asthma that needed medical attention outside scheduled appointments. On the basis of skin prick tests or specific serum IgE levels (radioallergosorbent test), the women were classified as atopic $(62 \%)$ or nonatopic $(38 \%)$. More than half of the atopic subjects (59\%) belonged to groups 1 and 2 (very mild or mild asthma), whereas most of the nonatopic subjects (59\%) belonged to groups 3 and 4 (moderately severe or severe asthma) $(P<0.05)$. Patients with nonatopic asthma had higher exacerbation and hospital admission rates than women with atopic asthma.

Carroll et $\mathrm{al}^{49}$ examined racial differences in the incidence of asthma exacerbations during pregnancy in a low income US population. A total of 112,171 eligible mother-infant pairs were identified; $43 \%$ of the mothers were African American. Compared with white Americans, African American women were more likely to be single (86\% versus $47 \%, P<0.001$ ), and live in urban areas $(76 \%$ versus $25 \%, P<0.001)$. The prevalence of asthma in the cohort was 2.7\% $(1285 / 47,856)$ among African Americans and 4.7\% (3030/64,315) among white Americans. During pregnancy, $12.7 \%(547 / 4315)$ of women with asthma received one or more courses of rescue corticosteroids. African American women were more likely to receive a course of steroids than white Americans (14.6\% and $11.9 \%$, respectively) (unadjusted rate ratio [RR] of 1.57 ; 95\% confidence interval [CI] 1.37-1.81), which remained significant after adjusting for age, education level, previous pregnancy, smoking status, high-risk pregnancy, region of residence in state, and delivery year (adjusted RR 1.35 , 95\% CI 1.14-1.61). Overall, $11.1 \%$ of women with asthma had an asthma-related ED visit during pregnancy. African American women were more likely to have an asthma-related ED visit than white Americans (16.7\% and $8.7 \%$, respectively, adjusted RR $1.89,95 \%$ CI 1.57-2.27). Overall, $6.3 \%$ of the women were hospitalized for asthma, and African American women had an increased rate of hospitalization compared with white Americans (9\% and 5.2\%, respectively, adjusted RR 1.73, 95\% CI 1.34-2.24). Therefore, ethnicity, primarily documented in African Americans, appears to be a significant risk factor for asthma exacerbation during pregnancy.

Other possible risk factors for exacerbation during pregnancy include obesity. ${ }^{50}$ The proportion of overweight and obese women in the reproductive age has increased, and maternal obesity is associated with increased risk of pregnancy-related complications. ${ }^{51}$ Furthermore, obesity has a negative impact on asthma severity and control. ${ }^{52}$ Hendler et $\mathrm{al}^{50}$ have shown that obesity is associated with an increased risk of asthma exacerbations during pregnancy based on data from a study comprising 906 women with mild asthma, 906 with moderate-severe asthma, and 928 controls. The proportion of pregnant women who were obese (body mass index $\geq 30 \mathrm{~kg} / \mathrm{m}^{2}$ ) was higher among cases with asthma compared with nonasthma controls $(30.7 \%$ and $25.5 \%$, respectively, $P=0.006$ ). A total of $32 \%$ of women with moderate-severe asthma and $29.2 \%$ of the women with mild asthma $(P=0.19)$ were obese, compared with $25.5 \%$ in the control group $(P=0.002)$. Obesity was associated with an increase in asthma exacerbations during pregnancy, which remained significant after adjusting for potential confounding variables (relative risk 1.3, 95\% CI 1.1-1.7, $P=0.01$ ), but not with other indicators of asthma severity, including steroid treatment. Women with asthma exacerbations requiring hospitalization had a higher mean body mass index than women who were not hospitalized for asthma during pregnancy. Similar to findings in nonpregnant patients with asthma, obesity is associated with difficult-to-control asthma and a higher risk of acute exacerbations during pregnancy.

The increase in serum progesterone during pregnancy causes relaxation of the smooth muscle in the lower esophageal sphincter, which may result in reflux. ${ }^{54}$ In asthma, reflux has been associated with poorer asthma control, and treatment of reflux has improved asthma symptoms. Reflux may, therefore, be associated with a higher risk of exacerbations 
during pregnancy, although the available evidence for this association is very limited.

It is well known that smoking is probably the most modifiable risk factor of asthma, and smoking during pregnancy is a significant risk factor for poor perinatal outcome, including low birth weights, premature birth, and infant mortality. ${ }^{55}$ However, Murphy et $\mathrm{l}^{56}$ was the first to assess the clinical implications of smoking on asthma exacerbations in pregnancy. In a prospective study, they followed pregnant women (18-43 years) with physician-diagnosed asthma $(n=85)$ from recruitment (mean 14.8, standard deviation [3.0] weeks gestational age) with clinic visits at $\sim 18,30$, and 36 weeks of gestation (visits 1, 2, and 3), and biweekly phone calls between visits. Women were seen for clinical evaluation during exacerbation if possible. Pregnant women were consecutively recruited through the John Hunter Hospital antenatal clinics and from the community between July 2004 and December 2006. The asthma control questionnaire score was administered at each contact, and included information related to severity of night-time awakenings, morning asthma symptoms, activity limitations, shortness of breath, wheezing, short acting $\beta_{2}$-agonist use, and lung function. A higher questionnaire score indicated worse asthma control. Asthma exacerbations were assessed prospectively during the study period, and retrospectively for the first part of pregnancy, with details confirmed by the medical records. Severe exacerbations were defined as requiring medical intervention (hospital admission, ED presentation, unscheduled doctor visit, or the use of oral corticosteroids). Mild exacerbations were defined as those managed by the subject and self-reported as increased symptoms or medication use (ICS or $\beta_{2}$-agonists), or using a written action plan. During clinical assessments height, weight, smoking history, spirometry, exhaled nitric oxide and exhaled carbon monoxide were assessed. Murphy et $\mathrm{al}^{45}$ found that women with asthma were more likely to smoke (34\% current smokers) than women without asthma (15\% current smokers). In women with asthma, the median interquartile range exacerbation rate during pregnancy was 2.0 (1.0-3.0) in current smokers, 2.0 (1.0-3.0) in exsmokers and $1.5(1.0-2.0)$ in women with no history of smoking. The asthma control score during exacerbations was higher in current smokers (median interquartile range 2.17 [1.17-2.7]) compared with women who never smoked (1.17 [0.8-2.17]), although the difference was not statistically significant. An adjusted linear regression model found that smoking was significantly associated with higher asthma control score during exacerbations $(P=0.04)$. Based on these observations, the authors concluded that asthma exacerbations are more common and more severe in current smokers compared with women who had never smoked.

\section{Discussion}

Asthma continues to impose a significant, and likely increasing, clinical and economic burden on patients and society. Asthma is the most common chronic disease in pregnancy, complicating $4 \%-8 \%$ of pregnancies. ${ }^{57}$ The course of asthma is changed by pregnancy, and the incidence of asthma exacerbations is high. The mechanisms that lead to asthma exacerbations during pregnancy are poorly understood, but viral infections and discontinuation of antiinflammatory medications are likely to be important..$^{27,28,33,34}$ A major contributor to exacerbations during pregnancy is the lack of appropriate treatment, especially controller therapy. Under-treatment, which remains a problem during pregnancy, leads to lack of sufficient asthma control. The concern that the treatment can harm the infant leads to nonadherence to medication, ${ }^{29}$ an increased risk of exacerbation, and negative impact on the health of the fetus. ${ }^{58}$

Current guidelines recommend a proactive approach to the care of the pregnant patient, which minimizes frequency and severity of exacerbations and maximizes asthma control to optimize the health of both the mother and the unborn child. ${ }^{59-61}$ Care of the pregnant patient with asthma requires a multifaceted approach focused on identifying patient-specific risk factors, which may increase her risk for worsening asthma control during pregnancy. Careful attention to medication nonadherence and under-treatment, combined with the development of self-management programs, may empower women and their health care providers to make well-informed decisions about this common, chronic medical condition in pregnancy. ${ }^{62}$ Pregnant women with asthma should be considered as having a high risk for complications and adverse outcome, and should, therefore, be managed closely by both obstetricians and asthma specialists.

In conclusion, the available studies document that the incidence of asthma exacerbations during pregnancy is disturbingly high, whereas the underlying mechanisms are incompletely understood. More severe asthma, better described as difficult-to-control asthma, nonadherence with controller therapy, viral infections, obesity, and ethnicity are likely to be important risk factors for exacerbations of asthma during pregnancy, whereas inconsistent findings have been reported with regard to the importance of sex of the fetus. More knowledge, preferably from prospective studies, is clearly needed in order to more precisely identify risk factors for exacerbations of asthma during pregnancy. 


\section{Disclosure}

The authors report no conflicts of interest in this work.

\section{References}

1. To T, Stanojevic S, Moores G, et al. Global asthma prevalence in adults: findings from the cross-sectional world health survey. BMC Public Health. 2012;12:204.

2. Akinbami OJ, Moorman JE, Liu X. Asthma prevalence, health care use, and mortality: United States, 2005-2009. Natl Health Stat Report. 2011;(32):1-14.

3. Murphy VE, Gibson PG, Smith R, Clifton VL. Asthma during pregnancy: mechanisms and treatment implications. Eur Respir J. 2005;25(4):731-750.

4. Murphy VE, Gibson PG. Premenstrual asthma: prevalence, cycle-tocycle variability and relationship to oral contraceptive use and menstrual symptoms. J Asthma. 2008;45(8):696-704.

5. Zemp E, Schikowski T, Dratva J, Schindler C, Probst-Hensch N. Asthma and the menopause: a systematic review and meta-analysis. Maturitas. 2012;73(3):212-217.

6. Contreras G, Gutiérrez M, Beroiza T, et al. Ventilatory drive and respiratory muscle function in pregnancy. Am Rev Respir Dis. 1991; 144(4):837-841.

7. Nelson-Piercy C, Waldron M, Moore-Gillon J. Respiratory disease in pregnancy. Br J Hosp Med. 1994;51(8):398-401.

8. Wise RA, Polito AJ, Krishnan V. Respiratory physiologic changes in pregnancy. Immunol Allergy Clin North Am. 2006;26(1):1-12.

9. Liberatore SM, Pistelli R, Patalano F, Moneta E, Incalzi RA, Ciappi G. Respiratory function during pregnancy. Respiration. 1984;46(2): $145-150$.

10. Brancazio LR, Laifer SA, Schwartz T. Peak expiratory flow rate in normal pregnancy. Obstet Gynecol. 1997;89(3):383-386.

11. National Asthma Education and Prevention Program. Working Group Report on Managing Asthma During Pregnancy: Recommendations for Pharmacologic Treatment. Bethesda, MD: US Department of Health and Human Services; 2004.

12. Cohn L, Elias JA, Chupp GL. Asthma: mechanisms of disease persistence and progression. Annu Rev Immunol. 2004;22:789-815.

13. Ferreira MA. Inflammation in allergic asthma: initiating events, immunological response and risk factors. Respirology. 2004;9(1):16-24.

14. Wenzel S. Mechanisms of severe asthma. Clin Exp Allergy. 2003; 33(12):1622-1628.

15. Wegmann TG, Lin H, Guilbert L, Mosmann TR. Bidirectional cytokine interactions in the maternal-fetal relationship: is successful pregnancy a TH2 phenomenon? Immunol Today. 1993;14(7):353-356.

16. McCracken SA, Gallery E, Morris JM. Pregnancy-specific downregulation of NF-kappa B expression in T cells in humans is essential for the maintenance of the cytokine profile required for pregnancy success. J Immunol. 2004;172(7):4583-4591.

17. Chaouat G, Ledee-Bataille N, Dubanchet S, Zourbas S, Sandra O, Martal J. Reproductive immunology 2003: reassessing the Th1/Th2 paradigm? Immunol Lett. 2004;92(3):207-214.

18. Wark PA, Johnston SL, Moric I, Simpson JL, Hensley MJ, Gibson PG. Neutrophil degranulation and cell lysis is associated with clinical severity in virus-induced asthma. Eur Respir J. 2002;19(1):68-75.

19. Simpson JL, Scott R, Boyle MJ, Gibson PG. Inflammatory subtypes in asthma: assessment and identification using induced sputum. Respirology. 2006;11(1):54-61.

20. Taniguchi K, Nagata H, Katsuki T, et al. Significance of human neutrophil antigen-2a (NB1) expression and neutrophil number in pregnancy. Transfusion. 2004;44(4):581-585.

21. Sacks G, Sargent I, Redman C. An innate view of human pregnancy. Immunol Today. 1999;20(3):114-118.

22. Murphy VE, Clifton VL, Gibson PG. Asthma exacerbations during pregnancy: incidence and association with adverse pregnancy outcomes. Thorax. 2006;61(2):169-176.
23. Schatz M, Harden K, Forsythe A, et al. The course of asthma during pregnancy, post partum, and with successive pregnancies: a prospective analysis. J Allergy Clin Immunol. 1988;81(3):509-517.

24. Murphy VE, Gibson P, Talbot PI, Clifton VL. Severe asthma exacerbations during pregnancy. Obstet Gynecol. 2005;106(5 Pt 1): 1046-1054.

25. Schatz M, Dombrowski MP, Wise R, et al. Asthma morbidity during pregnancy can be predicted by severity classification. J Allergy Clin Immunol. 2003;112(2):283-288.

26. Beckmann CA. A descriptive study of women's perceptions of their asthma during pregnancy. MCN Am J Matern Child Nurs. 2002;27(2):98-102.

27. Kaptein AA, Hughes BM, Scharloo M, et al. Illness perceptions about asthma are determinants of outcome. J Asthma. 2008;45(6):459-464.

28. Dahlén I, Janson C. Anxiety and depression are related to the outcome of emergency treatment in patients with obstructive pulmonary disease. Chest. 2002;122(5):1633-1637.

29. Nordeng H, Ystrøm E, Einarson A. Perception of risk regarding the use of medications and other exposures during pregnancy. Eur J Clin Pharmacol. 2010;66(2):207-214.

30. Tata LJ, Lewis SA, McKeever TM, et al. Effect of maternal asthma, exacerbations and asthma medication use on congenital malformations in offspring: a UK population-based study. Thorax. 2008; 63(11):981-987.

31. Blais L, Beauchesne MF, Rey E, Malo JL, Forget A. Use of inhaled corticosteroids during the first trimester of pregnancy and the risk of congenital malformations among women with asthma. Thorax. 2007; 62(4):320-328.

32. Stenius-Aarniala BS, Hedman J, Teramo KA. Acute asthma during pregnancy. Thorax. 1996;51(4):411-414.

33. Apter AJ, Greenberger PA, Patterson R. Outcomes of pregnancy in adolescents with severe asthma. Arch Intern Med. 1989;149(11):2571-2575.

34. Hartert TV, Neuzil KM, Shintani AK, et al. Maternal morbidity and perinatal outcomes among pregnant women with respiratory hospitalizations during influenza season. Am J Obstet Gynecol. 2003;189(6):1705-1712.

35. Minerbi-Codish I, Fraser D, Avnun L, Glezerman M, Heimer D Influence of asthma in pregnancy on labor and the newborn. Respiration. 1998;65(2):130-135.

36. Gluck JC, Gluck P. The effects of pregnancy on asthma: a prospective study. Ann Allergy. 1976;37(3):164-168.

37. Jain S, Kamimoto L, Bramley AM, et al; for 2009 Pandemic Influenza A (H1N1) Virus Hospitalization Investigation Team. Hospitalized patients with 2009 H1N1 influenza in the United States, Apr-Jun 2009. N Engl J Med. 2009;361(20):1935-1944.

38. Rastogi D, Wang C, Lendor C, Rothman PB, Miller RL. T-helper type 2 polarization among asthmatics during and following pregnancy. Clin Exp Allergy. 2006;36(7):892-898.

39. Centers for Disease Control and Prevention (CDC). Influenza vaccination coverage among pregnant women - 29 States and New York City, 20092010 season. MMWR Morb Mortal Wkly Rep. 2012;61(7):113-118.

40. Fiore AE, Uyeki TM, Broder K, et al; for Centers for Disease Control and Prevention (CDC). Prevention and control of influenza with vaccines: recommendations of the Advisory Committee on Immunization Practices (ACIP), 2010. MMWR Recomm Rep. 2010;59(RR-8):1-62.

41. Zaman K, Roy E, Arifeen SE, et al. Effectiveness of maternal influenza immunization in mothers and infants. $N$ Engl J Med. 2008;359(15): $1555-1564$.

42. Heinonen OP, Shapiro S, Monson RR, Hartz SC, Rosenberg L, Slone D. Immunization during pregnancy against poliomyelitis and influenza in relation to childhood malignancy. Int J Epidemiol. 1973;2(3): 229-235.

43. Beecroft N, Cochrane GM, Milburn HJ. Effect of sex of fetus on asthma during pregnancy: blind prospective study. BMJ. 1998;317(7162): 856-857.

44. Kwon HL, Belanger K, Holford TR, Bracken MB. Effect of fetal sex on airway lability in pregnant women with asthma. Am J Epidemiol. 2006;163(3):217-221. 
45. Murphy VE, Gibson PG, Giles WB, et al. Maternal asthma is associated with reduced female fetal growth. Am J Respir Crit Care Med. 2003; 168(11):1317-1323.

46. Firoozi F, Ducharme FM, Lemiére C, et al. Effect of fetal gender on maternal asthma exacerbations in pregnant asthmatic women. Respir Med. 2009;103(1):144-151.

47. Baibergenova A, Thabane L, Akhtar-Danesh N, Levine M, Gafni A. Is fetal gender associated with emergency department visits for asthma during pregnancy? J Asthma. 2006;43(4):293-299.

48. Stenius-Aarniala B, Piirilä P, Teramo K. Asthma and pregnancy: a prospective study of 198 pregnancies. Thorax. 1988;43(1):12-18.

49. Carroll KN, Griffin MR, Gebretsadik T, Shintani A, Mitchel E, Hartert TV. Racial differences in asthma morbidity during pregnancy. Obstet Gynecol. 2005;106(1):66-72.

50. Hendler I, Schatz M, Momirova V, et al; for National Institute of Child Health and Human Development Maternal-Fetal Medicine Units Network. Association of obesity with pulmonary and nonpulmonary complications of pregnancy in asthmatic women. Obstet Gynecol. 2006;108(1):77-82.

51. Poston L, Harthoorn LF, Van Der Beek EM; for Contributors to the ILSI Europe Workshop. Obesity in pregnancy: implications for the mother and lifelong health of the child. A consensus statement. Pediatr Res. 2011;69(2):175-180.

52. Taylor B, Mannino D, Brown C, Crocker D, Twum-Baah N, Holguin F. Body mass index and asthma severity in the National Asthma Survey. Thorax. 2008;63(1):14-20.

53. Fisher RS, Roberts GS, Grabowski CJ, Cohen S. Altered lower esophageal sphincter function during early pregnancy. Gastroenterology. 1978;74(6):1233-1237.
54. Harding SM. Gastroesophageal reflux and asthma: insight into the association. J Allergy Clin Immunol. 1999;104(2 Pt 1):251-259.

55. Einarson A, Riordan S. Smoking in pregnancy and lactation: a review of risks and cessation strategies. Eur J Clin Pharmacol. 2009; 65(4):325-330.

56. Murphy VE, Clifton VL, Gibson PG. The effect of cigarette smoking on asthma control during exacerbations in pregnant women. Thorax. 2010;65(8):739-744.

57. Kwon HL, Triche EW, Belanger K, Bracken MB. The epidemiology of asthma during pregnancy: prevalence, diagnosis, and symptoms. Immunol Allergy Clin North Am. 2006;26(1):29-62.

58. Murphy VE, Namazy JA, Powell H, et al. A meta-analysis of adverse perinatal outcomes in women with asthma. BJOG. 2011;118(11): 1314-1323.

59. Kwon HL, Belanger K, Bracken MB. Asthma prevalence among pregnant and childbearing-aged women in the United States: estimates from national health surveys. Ann Epidemiol. 2003;13(5):317-324.

60. National Asthma Education and Prevention Program. Expert Panel Report 3 (EPR-3): Guidelines for the diagnosis and management of asthma-summary report 2007. J Allergy Clin Immunol. 2007; 120(Suppl 5):S94-S138.

61. National Heart, Lung, and Blood Institute; National Asthma Education and Prevention Program Asthma and Pregnancy Working Group. NAEPP expert panel report. Managing asthma during pregnancy: recommendations for pharmacologic treatment-2004 update. JAllergy Clin Immunol. 2005;115(1):34-46.

62. McCallister JW. Asthma in pregnancy: management strategies. Curr Opin Pulm Med. 2012;19(1):13-17.

\section{Publish your work in this journal}

The Journal of Asthma and Allergy is an international, peer-reviewed open-access journal publishing original research, reports, editorials and commentaries on the following topics: Asthma; Pulmonary physiology; Asthma related clinical health; Clinical immunology and the immunological basis of disease; Pharmacological interventions and

\section{Dovepress}

new therapies. Issues of patient safety and quality of care will also be considered. The manuscript management system is completely online and includes a very quick and fair peer-review system, which is all easy to use. Visit http://www.dovepress.com/testimonials.php to read real quotes from published authors. 